\title{
PSYCHOSOCIAL ADAPTATION OF DONOR KIDNEY RECIPIENTS IN THE POST-OPERATIVE PERIOD
}

\author{
L.Baranskaia, K. Obukhova \\ Ural State Medical University, Yekaterinburg, Russia
}

\section{Background}

Any surgical intervention, regardless of the amount and duration, is a stressor for the patient, which affects somatic, mental health and psychological well-being of the patient.

However, while receiving the greatest popularity in medicine, the physiological stress concept (Selye, 1956., 1974; Greenberg, 2000 etc.) cannot explain the reasons for the increasing or decreasing the quality of life of patients undergoing surgery.

Attempts to analyze from the point of view of immediate danger to the patient in the case of surgical intervention, also little clarified the essence of subsequent changes.

The biopsychosocial model allows us to see the formation of a new body image after organ transplantation as a structure of self-consciousness.

The purpose of this study is to discover the conditions of successful psychosocial adaptation in the postoperative period in the cognitive, emotional, and communicative functions of the recipient's personality.

\section{Materials and Methods:}

Three hundred and twelve patients, both male and female, were studied during 12 years at the Sverdlovsk Regional Hospital No.1. The average age was $42.44 \pm 10.57$ years. The time of observation after kidney transplantation was $12.0 \pm 6.75$ months.

We used: Clinical interview, Beck's Depression scale, Attitude to Illness test, G. Rorschach's projective method, T.F. Cash's method of Body Image Assessment, Dembo-Rubinstein's method of measuring Self-Esteem, and Machover's test of drawing the human figure.

\section{Results and Conclusions}

The study showed significant correlations $(p \leq 0.01)$ between the image of the body, self-esteem, strategies of self-control and post-operative psychosocial adaptation.

Based on study results, the recipients were divided into 3 groups.

The first group, $72.1 \%$ of the recipients (225 patients), assessed the operation positively not only from survival point of view, but also as a possibility to carry out their plans with family, their professional and personal development.

The second group, 16.3\% (51 patients), were not so definite in their assessment: they saw it as a positive method of modern treatment but saw it negatively as life perspectives and future.

The third group, $11.6 \%$ (36 patients) experienced anxiety, depression, and bodily discomfort.

The quality of life of the kidney recipients and their psychosocial adaptation are interconnected constructs that determine overall functioning

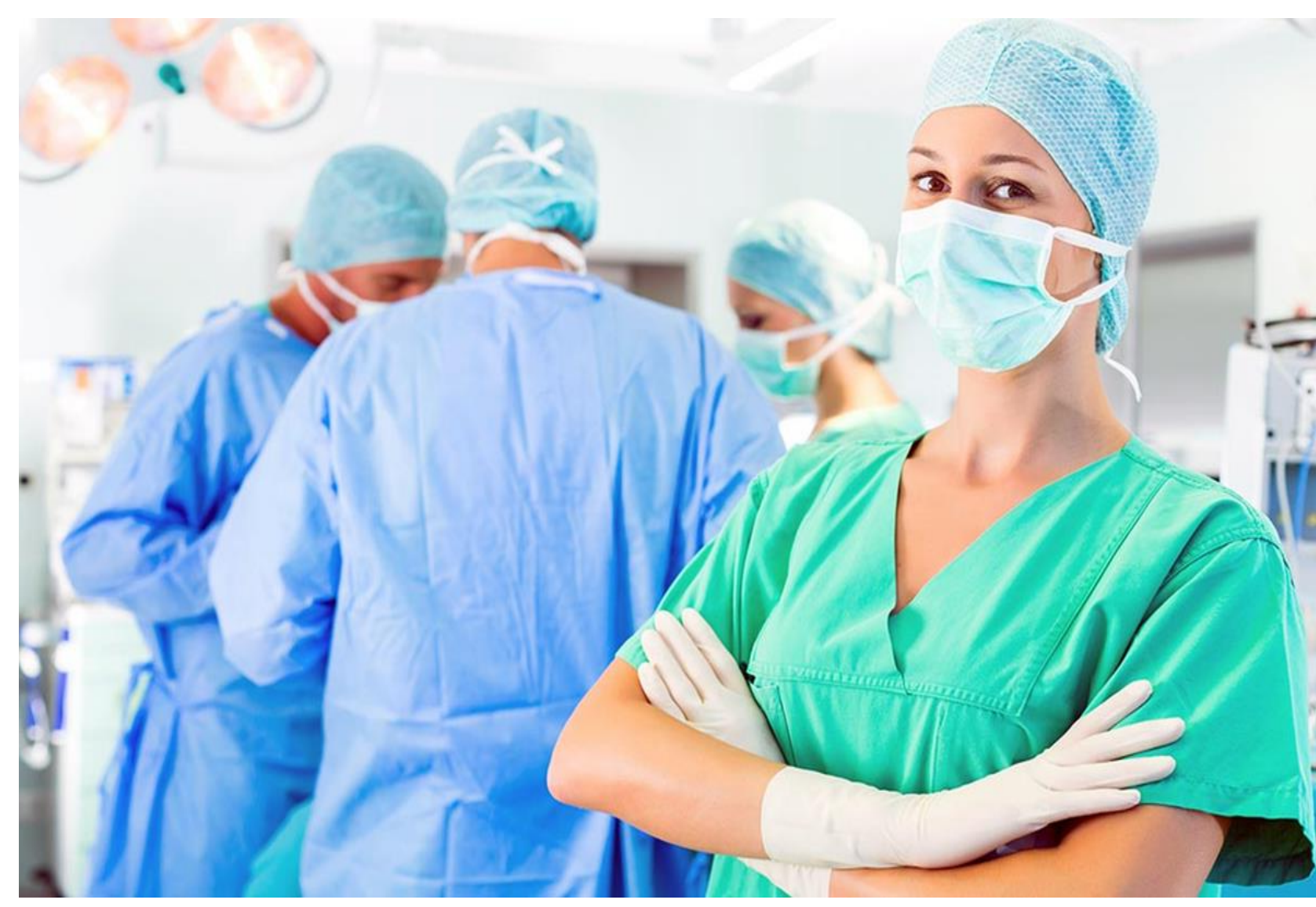

Copyright @ 2017 Author Names and Contact Details 